\title{
CryoLand - GMES Service Snow and Land Ice - Interoperability, Service Integration and User Access
}

\author{
Gerhard Triebnig ${ }^{1}$, Andrei Diamandi ${ }^{2}$, Richard Hall ${ }^{3}$, Eirik Malnes ${ }^{4}$, \\ Lars Marklund ${ }^{5}$, Sari Metsämäki ${ }^{6}$, Thomas Nagler ${ }^{7}$, Jouni Pulliainen ${ }^{8}$, Helmut Rott ${ }^{7}$, \\ Christian Schiller ${ }^{1}$, Rune Solberg ${ }^{9}$, and Andreas Wiesmann ${ }^{10}$ \\ ${ }^{1}$ EOX IT Services GmbH, Thurngasse 8/4, 1090 Wien, Austria \\ \{gerhard.triebnig, christian.schiller\} @eox.at \\ ${ }^{2}$ Administratia Nationala de Meteorologie R.A., Sos Buchuresti-Ploiesti 97, \\ Buchuresti Sectorul 1, 013686, Romania \\ diamandi@meteoromania.ro \\ ${ }^{3}$ Kongsberg Satellite Services AS, Prestvannveien 38, 9011 Tromsoe, Norway \\ richard@ksat.no \\ ${ }^{4}$ Northern Research Institute, Sykehusveien 21, Forskningsparken I, Tromsoe AS, Norway \\ eirikanorut.no \\ ${ }^{5}$ Swedish Meteorological and Hydrological Institute, Folksborgsvaegen 1, \\ Norrkoeping, 60176 Sweden \\ lars.marklundesmhi.se \\ ${ }^{6}$ Suomen Ymparistokeskus, Mechelininkatu 34a, 00251 Helsinki, Finland \\ sari.metsamaki@ymparisto.fi \\ ${ }^{7}$ ENVEO Environmental Earth Observation IT GmbH, Technikerstrasse 21a, 6020 \\ Innsbruck, Austria \\ \{thomas.nagler, helmut.rott\} @enveo.at \\ ${ }^{8}$ Ilmatieteen Laitos, Erik Palmenin aukio 1, 99600 Sodankylä, Finland \\ jouni.pulliainenafmi.fi \\ ${ }^{9}$ Norwegian Computing Center, \\ Gaustadalleen 23, 0371 Oslo, Norway \\ rune.solberg@nr.no \\ ${ }^{10}$ GAMMA Remote Sensing Research and Consulting AG, Worbstrasse 225, \\ 3073 Gumlingen, Switzerland \\ wiesmannegamma-rs.ch
}

\begin{abstract}
The CryoLand project implements and validates a standardized and sustainable service on snow and land ice monitoring as a Downstream Service of GMES. It will provide geospatial product coverages of seasonal snow (snow extent, snow mass, melt state), glaciers (area, snow / ice extent, ice velocities, glacier dammed lakes), and lake / river ice (extent, temporal variations, snow burden) derived from Earth observation (EO) satellite data. Processing lines and a service infrastructure will be developed on top of existing Web service environments supporting the publication, provision and chaining of involved geospatial data services. The CryoLand service architecture commits INSPIRE, OGC, and OASIS standards specifically respecting HMA and GENESIS frameworks. User information services offering discovery, view and download functions will be provided.
\end{abstract}

Keywords: snow, glacier, ice, spatial data infrastructure, service architecture. 


\section{Introduction}

The CryoLand project [1] is expected to establish new snow and land ice service capacities targeting its specified user communities. It will provide geospatial products on snow extent and snow pack physical properties, maps of glacier area and other glacier parameters, and on fresh water ice from EO data. Significant uptake of these products and suitable business models for long-term operational supply will have to be supported.

This paper describes preliminary results of the service requirements and system architecture definition activities aiming at setting-up the spatial data infrastructure of CryoLand including the interfaces for interoperability with neighbouring systems and to end-users.

\section{Infrastructure Requirements}

\subsection{High-Level Requirements}

The CryoLand Infrastructure will be designed to support advancements of product generation chains (e.g. for automatic integration of space and in-situ data into hydrological process models) including tools for Sentinel-based snow and ice products as well as chains for product delivery in near-real-time after (satellite) observation. It will be the platform for testing and validation of snow and ice products tailored to user needs and the associated product generation and access services. It will also serve for demonstration, training and service up-take activities by identified external customers.

A GMES-embedded, pre-operational, Internet-based service infrastructure shall be designed such as to be transferrable at the end of the project into sustainably operational multi-provider environments.

\subsection{Neighbouring Systems}

Fig. 1 shows how the CryoLand system will conceptually be surrounded by other infrastructures.

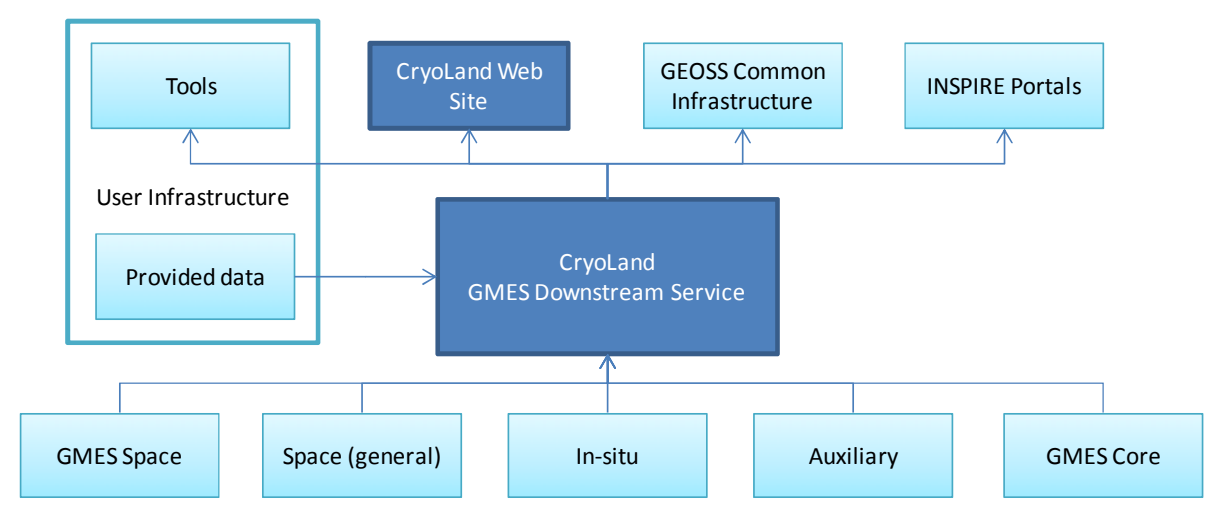

Fig. 1. CryoLand and its neighbouring systems 
A significant number of external interfaces will have to be dealt with in order to integrate CryoLand's snow and ice services into the wider geospatial infrastructure. A heterogeneous set of input data sources will have to be connected. Furthermore, the CryoLand services must be prepared for being consumed by a (yet unknown) number of client-side systems supporting virtual and real users. There is also the requirement to establish native access via the CryoLand's own Web site.

\section{CryoLand Architecture}

\subsection{Architecture Definition Approach}

The CryoLand architecture elements for (1) user access, (2) service integration, and (3) data storage management are being defined, designed, implemented and documented in alignment with the definition and design of the thematic snow and ice processing and product generation services. The architecture definition methodology applied is based on RM-ODP (ISO 10746) which essentially requests to look at the architecture from the interrelated "five viewpoints" as further explained in sections 3.3 through 3.7 .

\subsection{Architecture Baseline and Good Practice}

CryoLand attempts to build on the state-of-the-art for geospatial data systems with particular considerations on good practice in EO satellite payload data ground segment infrastructures. The following is a summary of the areas impacting the design of the CryoLand infrastructure:

- INSPIRE geodata infrastructure standards framework and implementing rules

- OGC geospatial standards/tools framework and best practices

- OASIS security standards

- FP7 GENESIS environmental service concepts and software re-use

- Heterogeneous Missions Accessibility (HMA) framework and GMES Coordinated Data access Service

- FP7 geoland2 concepts, interoperability requirements and service interfaces

- Other GMES Core and Downstream Infrastructures (PASODOBLE, ENDORSE, etc.)

- ESA algorithm development, processing, service support environments and user service interfaces (KEO, G-POD, SSE, ngEO)

- GEOSS Common Infrastructure integration

Legacy snow mapping infrastructures provided by CryoLand project partners (who themselves are involved in a range of national and international thematically related projects) are, naturally, the starting points of the good practice analysis. The CryoLand project is performing a thorough assessment of this legacy and heritage in order to define re-use and evolution strategies from existing and available infrastructure solutions. 


\subsection{Enterprise Viewpoint}

This RM-ODP (see section 3.1) viewpoint asks for the definition of CryoLand's purpose, scope, policies, and related business which altogether are impacting infrastructure implementation decisions. In addition to the high-level requirements stated in section 2.1 the infrastructure shall support:

- Higher automation degree of processing lines, workflows and logistics

- Coordinated data storage management

- Standard interfaces of network services and for user access (INSPIRE and GEOSS compliant)

- Services operations in multi-provider environment

- Validation of Sentinel-1 utility and service lines

- Production facilities for European Climate Change Initiative (probably)

The implementing organizations (i.e. the FP7 consortium partners - see affiliation list of paper authors) and some 40 formally committed user organizations are in the process of formulating their different operational mandates, commitments and business expectations related to the future sustained operations of the CryoLand provided services.

\subsection{Information Viewpoint}

This viewpoint is concerned with the semantics of information or products as well as of the information processing to be implemented by CryoLand. The CryoLand Information Model - aligned with OGC geospatial information model - will define in all details the complete sets of (1) Applications and Output Products - see Table 1, (2) Input Data/Products, and (3) System Management Data/Information. Building on results from [2], [3], [4] and [5] it will also describe the algorithms of choice which will generate information and knowledge from data. This will be the data processing recipes for e.g. improving the quality of the snow cover products, in particular in forested regions and in areas of complex land use; for capitalizing on the enhanced sensor characteristics and coverage of the GMES Sentinel satellite series; for the integration of systematic in-situ measurements and remote sensing data; and the like.

Table 1. CryoLand applications and output product groups (preliminary)

\begin{tabular}{ll}
\hline Topic & Main Parameters \\
\hline Seasonal Snow & $\begin{array}{l}\text { Snow extent, snow mass, melt state of snow (wet / dry) } \\
\text { Glaciers }\end{array}$ \\
Glacier outline (area), snow / ice extent, ice velocity, \\
glacier dammed lakes
\end{tabular}

The extensive list of Input Data/Products corresponding to the input data interfaces indicated in Fig. 1 will include optical EO data (including when available: Seninel-2 \& -3), radar feeds (Sentinel-1), in-situ/reference data (e.g. topography models), and GMES Core Service products (e.g. Pan-European Degree of Soil Sealing). 
In Table 2 a preliminary list of System Management Data types is shown which will be essential for the functioning of the CryoLand services. Very relevant in the definition of these data will be the OGC Geospatial Information Model [1] since it standardizes geographic features (and mark-up language), spatial referencing, geometry and topology, and provides OGC Schema Repositories and many more important elements.

Table 2. CryoLand system management data/information (non-comprehensive)

\begin{tabular}{ll}
\hline Use & Data / Information \\
\hline Security \& User Management & $\begin{array}{l}\text { Authentication and Authorization Data, } \\
\text { Access Policies }\end{array}$ \\
Discovery Service \& Annotations & Metadata \\
Service & Geo Data Visualizations \\
Portrayal Service & EO Datatsets, \\
Archive \& Resource Management & EO Dataset Metadata, \\
Service & $\begin{array}{l}\text { In-situ Datatsets } \\
\text { Service Registration Data, Process } \\
\text { Workflow Services }\end{array}$ \\
& Metadata \\
\hline
\end{tabular}

\subsection{Computational (Service) Viewpoint}

This viewpoint is concerned with the functional decomposition of the overall CryoLand system into a set of services that interact at interfaces. The design activites will fully draw upon the OGC Service Model [7] which establishes the principles for the service oriented architecture and points to the extensive set of specifications related to the OGC Web Services. A number of those will be essential to implement interoperable CryoLand service interfaces.

Table 3. Abstract service types to be implemented by CryoLand based on OWS specifications

\begin{tabular}{ll}
\hline OGC Web Service (OWS) & Abstract service / Use \\
\hline CSW & Catalogue \\
WFS (-T) & Download Feature \\
WMS \& EO AP & View/Portrayal \\
WCS (-T) \& EO AP & Download Coverage \\
SOS & Sensor Observation \\
SPS & Sensor Planning \\
WPS & Processing Invocation \\
\hline -T = Transactional (Upload) & AP = Application Profile \\
\hline
\end{tabular}

For the implementation of raster data flows (up- und downloads) between CryoLand system components the Web Coverage Service and its transactional extension (WCS-T) is considered a capable mechanism. In particular the recent developments of the EO Application Profile of WCS 2.0 [8] demonstrate the 
usefulness of this protocol in the distributed facility organization of CryoLand (see section 3.7).

\subsection{Technology Viewpoint}

This viewpoint will address the specific software to be used for the implementation of the CryoLand service components and make decisions on the hardware platforms which are needed for deployment and hosting of the software instances. The project has an orientation towards Free and Open Source Software (FOSS) but not made any decisions so far on the specific software platforms for the system at the various stages of evolution.

\subsection{Engineering Viewpoint}

This viewpoint defines a set of components that provide the basis for deployment of the CryoLand system in a distributed environment as shown in Fig. 2. These engineering components are accessed by services (see section 3.5).

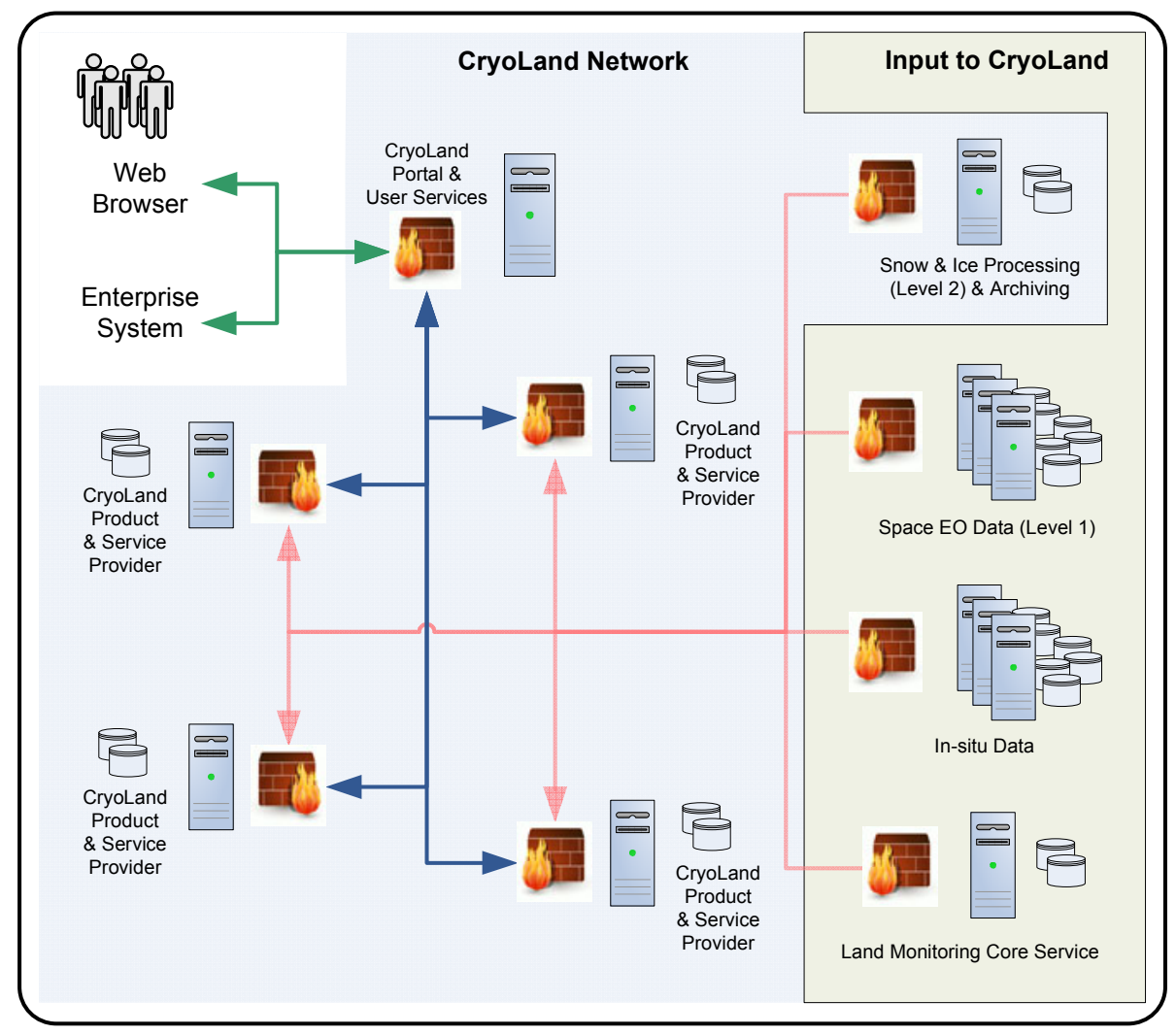

Fig. 2. CryoLand multi-provider \& distributed network 
The CryoLand Engineering Model - aligned with OGC model of reusable patterns for deployment - foresees a multi-tier architectures with a number of distributed nodes representing CryoLand service partners each acting as processing and service provider. The Spatial Data Infrastructures will link these nodes with the input data providers. These include space EO data acquisition and archiving centres providing Level-1 data (calibrated, swath-based satellite data), e.g. ESA processing and archiving centres (PAFs), the KSAT PAF, etc. Another important link is with the GMES Land Monitoring Core Service (LMCS) centre, as LMCS products will be integrated with satellite data for producing enhanced satellite snow products of CryoLand. Links to in-situ data providers (archives) will be set up according to user needs. Additionally, the CryoLand service concept foresees to maintain a Level-2 product archive (swath-based geophysical product, e.g. snow area extent) if required. This facilitates the production of customized (Level-3) satellite-based products that are derived from the same basic input data. Each node will be protected under a jointly organized security scheme. The interface for the users to the individual CryoLand nodes will be through a portal, providing virtual centralized access to the decentralized, chained services and the generated products.

\section{Status of Development}

The starting points of the CryoLand project are offerings of legacy snow and ice services available at project partner organizations. Based on user requirements assessed within the early project phase the services and products will be harmonized and tailored to match the customer needs. The infrastructure is already and will remain - by principle - distributed to designated service operators with a unique reference Web location [1] providing a logical entry point to these services. Currently a number of WMS-based viewing services to snow products are shown for demonstration purposes. Furthermore, a collection of example products is put online to indicate the future CryoLand product portfolio by showing early results.

\section{Conclusion and Outlook}

A GMES-embedded, pre-operational, Internet-based service infrastructure supporting the generation and provision of seasonal snow, glaciers, and lake / river ice information products is designed and will be implemented by the CryoLand project such as to be transferrable into sustainably operational multi-provider environments at project end. The overall project time span is February 2011 to January 2015 with service pre-operations and consolidation during 2013 - 2014. Services and products making use of data from the first GMES satellite Sentinel-1 (currently planned for launch in the first quarter of 2013) are expected during 2014.

\section{Acknowledgements}

The work described in this paper is partly supported by funding from the European Community's Seventh Framework Programme ([FP7/2007-2013]) under Grant Agreement n ${ }^{\circ} 262925$. 


\section{References}

1. CryoLand Project Web Page, http: / /www. cryoland.eu/

2. Malnes, E., Storvold, R., Lauknes, I., Solbø, S., Solberg, R., Amlien, J., Koren, H.: Multisensor monitoring of snow parameters in Nordic mountainous areas. In: Proc. IGARSS 2005, Seoul, South Korea, July 25-29 (2005)

3. Nagler, T., Rott, H.: Retrieval of wet snow by means of multitemporal SAR data. IEEE Trans. Geosci. Remote Sensing 38(2), 754-765 (2000)

4. Nagler, T., Rott, H.: Snow classification algorithm for Envisat ASAR. In: Proc. of Envisat \& ERS Symposium, Salzburg, Austria, p. 8 (September 2005), ESA SP-572

5. Solberg, R., Amlien, J., Koren, H., Eikvil, L., Malnes, E., Storvold, R.: Multi-sensor and time-series approaches for monitoring of snow parameters. In: Proc. of IGARSS 2004, Anchorage, Alaska, USA, September 20-24 (2004a)

6. OGC Geospatial Information Model, http: / /www.opengeospatial.org/standards/orm\#_Toc87953568

7. Geospatial Services Model, http: / /www.opengeospatial.org/standards / orm\#_Toc87953580

8. OGC 10-140 WCS Earth Observation Application Profile, https://portal.opengeospatial.org/files/?artifact_id=42579 as an OGC Standard 